\title{
A New MAP Kinase Protein Involved in Estradiol-Stimulated Reproduction of the Helminth Parasite Taenia crassiceps
}

\author{
Galileo Escobedo, ${ }^{1,2}$ Gloria Soldevila, ${ }^{3}$ Guadalupe Ortega-Pierres, ${ }^{4}$ \\ Jesús Ramsés Chávez-Ríos, ${ }^{3}$ Karen Nava, ${ }^{3,5}$ Rocío Fonseca-Liñán, ${ }^{4}$ Lorena López-Griego, ${ }^{3}$ \\ Claudia Hallal-Calleros, ${ }^{6}$ Pedro Ostoa-Saloma, ${ }^{3}$ and Jorge Morales-Montor ${ }^{3}$ \\ ${ }^{1}$ Departamento de Medicina Experimental, Facultad de Medicina, UNAM, Hospital General de México, México D.F. 06726, Mexico \\ ${ }^{2}$ Departamento de Biología, Facultad de Química, UNAM, AP 70228, México D.F. 04510, Mexico \\ ${ }^{3}$ Departamento de Inmunología, Instituto de Investigaciones Biomédicas, UNAM., AP 70228, México D.F. 04510, Mexico \\ ${ }^{4}$ Departamento de Genética y Biología Molecular, Cinvestav, IPN, Av. Instituto Politécnico Nacional 2508 Col. San Pedro Zacatenco, \\ México D.F. 07360, Mexico \\ ${ }^{5}$ Subdirección de Investigación Clínica, Instituto Nacional de Perinatología, México D.F. 11000, Mexico \\ ${ }^{6}$ Facultad de Farmacia, Universidad Autónoma del Estado de Morelos, Morelos 62209, Mexico
}

Correspondence should be addressed to Jorge Morales-Montor, jmontor66@biomedicas.unam.mx

Received 30 July 2009; Accepted 12 October 2009

Academic Editor: Luis I. Terrazas

Copyright ( $\odot 2010$ Galileo Escobedo et al. This is an open access article distributed under the Creative Commons Attribution License, which permits unrestricted use, distribution, and reproduction in any medium, provided the original work is properly cited.

MAP kinases (MAPK) are involved in the regulation of cellular processes such as reproduction and growth. In parasites, the role of MAPK has been scarcely studied. Here, we describe the participation of an ERK-like protein in estrogen-dependent reproduction of the helminth parasite Taenia crassiceps. Our results show that $17 \beta$-estradiol induces a concentration-dependent increase in the bud number of in vitro cultured cysticerci. If parasites are also incubated in presence of an ERK-inhibitor, the stimulatory effect of estrogen is blocked. The expression of ERK-like mRNA and its corresponding protein was detected in the parasite. The ERK-like protein was over-expressed by all treatments. Nevertheless, a strong induction of phosphorylation of this protein was observed only in response to $17 \beta$-estradiol. Cross-contamination by host cells was discarded by flow cytometry analysis. Parasite cells expressing the ERK-like protein were exclusively located at the subtegument tissue by confocal microscopy. Finally, the ERK-like protein was separated by bidimensional electrophoresis and then sequenced, showing the conserved TEY activation motif, typical of all known ERK 1/2 proteins. Our results show that an ERK-like protein is involved in the molecular signalling during the interaction between the host and T. crassiceps, and may be considered as target for anti-helminth drugs design.

\section{Introduction}

Cellular signaling is a crucial function for eukaryotic cells [1]. Complex molecule networks are involved in the cell's response to external signals and cross-communication among different physiological systems of the organism [2]. Transduction of cell signalling, which is mainly mediated by second messenger cascades, allows faster responses to a wide variety of stimuli [3-6], which control cellular functions such as proliferation, growth, and differentiation [2]. Among extracellular stimuli are steroid and protein hormones which are able to induce phosphorylation of membrane receptors with serine-threonine-tyrosine kinase activity which consti- tutes the initial process that will subsequently orchestrate the whole transduction pathway [7-10].

The mitogen-activated protein kinase family (MAPK) that contain various signaling molecules have received increasing attention due to their implications on cell growth and proliferation [2]. Furthermore, MAPKs are highly conserved along the evolutionary scale $[11,12]$ from invertebrates to mammals [11].

MAPKs are divided into three main groups: (1) Jun $\mathrm{NH}_{2}$ terminal kinases (JNK 1/2/3) which are mainly activated by cytokines and induce DNA damage. This MAPK has been associated with phosphorylation of c-jun. (2) p38 (p38 $\alpha / \beta / \gamma / \delta)$ that switches on in response to stress stimuli and 
has been related to osmoregulation and cell cycle entry. (3) Extracellular signal-regulated kinases (ERK 1/2) that can be activated by hormones associated to G-protein coupled receptors (GPCRs), growth factors, stress stimuli, cytokines, and Raf kinases, among others [2]. Two main isoforms have been described for ERK, ERK1, and ERK2, which have around $80 \%$ of homology in protein sequence $[2,13]$. During cell proliferation, ERK $1 / 2$ can activate, through specific phosphorylation of serine-proline/threonine-proline residues, several nuclear transcription factors, such as c-fos and c-jun, Elk1, c-myc, and STAT3, among others. All of these molecules are involved in cell cycle entry and regulation [14].

The role of ERK 1/2 during the molecular crosstalk between host and parasite is not clear yet, although it is present when the host synthesizes hormones and growth factors which directly benefit the parasite [15]. This bidirectional communication between the two organisms can occur due to the presence of parasitic structures that simulate the hosts' hormone receptors and ligand-binding proteins [15]. Concomitantly, little is known about the presence and function of ERK $1 / 2$ in parasites. For instance, ERK $1 / 2$ has been implied in the response of Echinococcus multilocularis to human epidermal growth factor (ERK-like MAP kinase) [16]. On the other hand, an ERK-like protein has been reported for Trypanosoma brucei and is involved in the parasite's growth rate [17].

Although some information is available regarding the presence of ERK homologs in parasites, not much is known on their function and possible role in mediating the parasite's response to the host's hormonal microenvironment, which occurs during an infection process, for example, in murine cysticercosis caused by Taenia crassiceps.

Experimentally induced murine cysticercosis represents an alternative model to study the parasite-host interaction similar to that occurring during human/porcine infection caused by Taenia solium [18]. Murine cysticercosis may be induced in both male and female mice by injecting the metacestode stage of the helminth parasite T. crassiceps into the mouse peritoneal cavity [19]. Interestingly, female mice of any strain are more susceptible than male mice and this effect is strongly related to the sex-steroid microenvironment [20]. It has been shown that $17 \beta$-estradiol $\left(\mathrm{E}_{2}\right)$ induces an increase in the parasite load by two mechanisms: tilting the hosts' immune response towards a parasite-permissive Th2 response [21] and directly promoting parasite growth and reproduction [22]. In this context, we reported that $\mathrm{E}_{2}$ increases in vitro reproduction of $T$. crassiceps while androgens inhibit it. The proliferative effect of $E_{2}$ on the parasite seems to be mediated by the estrogen-induced AP-1 transcription factor expression in the parasite [23]. Estrogen receptor (ER) expression by cysticerci and activation of the AP-1 complex, in addition to the inhibition of proliferation by tamoxifen, support the idea that one of the proliferative mechanisms mediated by $\mathrm{E}_{2}$ is a classical nuclear receptordependent pathway $[22,24]$.

However, the proliferative effect of $E_{2}$ on $T$. crassiceps reproduction is not fully inhibited by the antiestrogen tamoxifen suggesting that the parasite may respond to estrogens by alternative pathways, such as those mediated by the interaction between steroid hormones and GPCRs [25]. For instance, in excitable cells from mouse reproductive tissue, estrogens can promote GPCR activity [26], triggering to the epidermal growth factor receptor activation as well as phosphorylation of the PLC-PKC pathway [27]. On the other hand, $\mathrm{E}_{2}$ effects are not only mediated by unspecific receptors localized in the cellular membrane but also by means of the specific nuclear ER $[28,29]$. In fact, the binding between $\mathrm{E}_{2}$ and its membrane ER activates group I and II of the metabotropic glutamate receptor [30]. It should here be mentioned that ER is able to bind to SRC kinases through their highly conserved SH2 domains, which could considerably modify the effect of ERK $1 / 2$ on the phosphorylation pattern of this transcription factor [31]. Nevertheless, information on this type of mechanisms in parasitic cells is scarce $[16,17,32]$. Therefore further studies on these mechanisms are required particularly for drug design since the knowledge obtained on the metabolic pathways that regulate parasite growth and establishment could provide with specific potential targets for therapeutic treatment. These may involve enzymes, genes, and transduction molecules which are exclusively present in the parasite. Additionally, this would also avoid host damage and nonspecific cross responses.

The aim of this work was to find experimental evidence on the functional participation of alternative molecules that can respond to the estrogenic stimulus, as may be the case of a parasite ERK-like protein, which could mediate the proliferative effects of exogenous $17 \beta$-estradiol on the helminth parasite Taenia crassiceps. The study of signal transduction in this parasite may potentially benefit not only the understanding of the host-parasite molecular crosstalk but also the design of drugs that specifically arrest the activity of important parasite molecules such as transduction proteins and transcription factors.

\section{Materials and Methods}

2.1. Harvesting and Preparing Cysticerci for Experimentation. A new stock of T. crassiceps cysticerci (ORF-Kuhn2 strain) was donated to our laboratory by R. Kuhn in 2000 and was kept by serial intraperitoneal passage in BALB/c AnN female mice approximately every four months $[19,33]$. Cysticerci for each experimental session were obtained from intraperitoneally infected female mice and placed in tubes containing sterile PBS (1X) supplemented with $100 \mathrm{U} / \mathrm{mL}$ of antibiotics fungizone (Gibco, Grand Island). The tubes were centrifuged for 10 minutes at $1,500 \mathrm{rpm}$ and $4^{\circ} \mathrm{C}$, and the supernatant was discarded. Packed cysticerci were incubated in AIM-V serum-free medium (Sigma, St. Louis, Missouri). These were then centrifuged 3 times at $1,500 \mathrm{rpm}$ for 10 minutes for washing. After the final wash, the numbers of viable cysticerci (complete, translucent, and motile cystic structures) were counted under a binocular microscope. Ten viable nonbudding cysticerci of approximately $2 \mathrm{~mm}$ in diameter were then selected and dispensed into each well of 24-well culture plates (Falcon, Becton Dickinson Labware, 
Franklin Lakes, New Jersey) in $1 \mathrm{~mL}$ AIM-V Medium (Gibco $\mathrm{BRL}$ ) and incubated at $37^{\circ} \mathrm{C}$ and $5 \% \mathrm{CO}_{2}$. A sufficient number of culture wells were prepared to accommodate the complete experimental design to evaluate the effects of in vitro treatment of estradiol on cysticerci. Cultures were checked daily and their medium was completely replaced when neccesary.

2.2. In Vitro Treatment Effects of $E_{2}$ and ERK inhibitor on T. crassiceps Cysticercus Reproduction. Culture grade 17- $\beta$ estradiol $\left(E_{2}\right)$ was obtained from Sigma. Culture grade ERK inhibitor II was obtained from Calbiochem. For in vitro tests, water-soluble $E_{2}$ was dissolved in DMEM serum-free culture medium, and ERK inhibitor II was dissolved in 3\% DMSO. Each one was prepared to $100 \mu \mathrm{M}$ stock concentration and then sterilized by passage through a $0.2 \mathrm{~mm}$ millipore filter. Each of the following experimental conditions was applied to 24 parasite-loaded wells for concentration-response curves: (a) supplemented with the vehicle where hormones were dissolved (control groups), (b) separately supplemented with $0.1,0.5,1$, and $10 \mu \mathrm{M}$ of $E_{2}$ and (c) separately supplemented with $0.1,0.5,1$, and $10 \mu \mathrm{M}$ of ERK inhibitor II. Optimal concentrations of $E_{2}$ and ERK inhibitor II were selected from the concentration-response curves and used further on in time-response curves. Entire time of concentrationresponse and time-response curves was five days. The used concentrations were as follows: $0.1 \mu \mathrm{M}$ of $E_{2}$ and $0.5 \mu \mathrm{M}$ of ERK inhibitor II. The number of buds per cysticercus as a function of days in culture was assessed as the response variable. In parasites treated at the same time with estrogen and inhibitor, ERK inhibitor II was supplemented 2 hours before the addition of 17- $\beta$ estradiol. Parasite reproduction was measured by counting the total number of buds in the ten cysticerci in each well. Bud count, as well as viability, was checked daily under an inverted light microscope (Olympus, MO21, Tokyo, Japan) at $4 \times$ and $10 \times$ magnification. Injury to cysticerci was recognized microscopically by progressive internal disorganization, development of whitish opaque areas on the parasite's tegument, and loss of motility. Dead cysticerci were immobile, opaque, and structurally disorganized.

2.3. Detection of ERK-Like Gene Expression in T. crassiceps by RT-PCR. Total RNA was isolated from hormone and ERK inhibitor II-treated T. crassiceps cysticerci and $\mathrm{BALB} / \mathrm{c}$ AnN female mouse spleen (used as controls for specific ERK gene amplification, data not shown) by the single-step method based on guanidine isothiocyanate/phenol/chloroform extraction using Trizol reagent (Invitrogen, Carlsbad, CA). Briefly, cysticerci were disrupted in Trizol reagent $(1 \mathrm{~mL} / 0.1 \mathrm{~g}$ tissue), and $0.2 \mathrm{~mL}$ of chloroform was added per $1 \mathrm{~mL}$ of Trizol. The aqueous phase was recovered after 10 minutes centrifugation at $1,500 \mathrm{rpm}$. RNA was precipitated with isopropyl alcohol, washed with $75 \%$ ethanol, and dissolved in RNAse-free water. RNA concentration was determined by absorbance at $260 \mathrm{~nm}$ and its purity was determined by electrophoresis in $1.0 \%$ denaturing agarose gel in the presence of $2.2 \mathrm{M}$ formaldehyde. Once properly quantified, total RNA was reverse transcribed, followed by specific PCR amplification of ERK-like gene from parasite tissue, at the same time as $\beta$-actin (control gene), as previously described [22]. Briefly, $10 \mu \mathrm{g}$ of total RNA were incubated at $37^{\circ} \mathrm{C}$ for $\mathrm{h}$ with 40 units of M-MLV reverse transcriptase (Applied Biosystems, USA) in $20 \mu \mathrm{L}$ of reaction volume containing $50 \mu \mathrm{M}$ of each dNTP and $0.05 \mu \mathrm{g}$ oligo (dt) primer (Gibco, NY). Ten $\mu \mathrm{L}$ of the cDNA reaction were subjected to PCR in order to amplify the sequences of the specified genes. Primer design was based on the most conserved regions of sequenced genes of all species reported in the database. Sequences of primers are as follows: Erk sense 5'-ACAAAGTTCGAGTTGCTATCA$3^{\prime}$ and antisense $5^{\prime}$-ATTGATGCCAATGATGTTCTC- $3^{\prime}$ and $\beta$-actin sense $5^{\prime}$-GGGTCAGAAGGATTCCTATG and antisense $5^{\prime}$-GGTCTCAAACATGATCTGGG. The $50 \mu \mathrm{L}$ PCR reaction included $10 \mu \mathrm{L}$ of previously synthesized cDNA, $5 \mu \mathrm{L}$ of $10 \times$ PCR buffer (Perkin-Elmer, USA), $1 \mathrm{mM} \mathrm{MgCl}$, $0.2 \mathrm{mM}$ of each dNTP, $0.05 \mu \mathrm{M}$ of each primer, and 2.5 units of Taq DNA (Biotecnologias Universitarias, Mexico). After an initial denaturation step at $95^{\circ} \mathrm{C}$ for 5 minutes, temperature cycling was as follows: $95^{\circ} \mathrm{C}$ for 30 seconds, $57^{\circ} \mathrm{C}$ for 45 seconds, and $72^{\circ} \mathrm{C}$ for 45 seconds during 35 cycles. An extra extension step was completed at $72^{\circ} \mathrm{C}$ for 10 minutes for each gene. The $50 \mu \mathrm{L}$ of the PCR reaction were electrophoresed on $2 \%$ agarose gel in the presence of a $100 \mathrm{bp}$ ladder as molecular weight marker (Gibco, BRL, NY). The PCR products obtained were visualized by staining with ethidium bromide. In both cases, different PCR conditions were assessed until a single band corresponding to the expected molecular weight of the gene was found. The $\beta$-actin gene is a constitutively expressed gene, and it was used as internal control for differences in the amplification procedure between experiments and to stain different gels.

\subsection{ERK-Like Protein Detection on T. crassiceps by Western} Blot. Total protein was obtained from T. crassiceps cysticerci by conventional Tris- $\mathrm{HCl}$ isolation. Briefly, untreated, $\mathrm{E}_{2}$ and ERK inhibitor II-treated cysticerci were disrupted in Tris$\mathrm{HCl}(1 \mathrm{~mL} / 0.1 \mathrm{~g}$ tissue $)$, proteinase $\mathrm{K}(100 \mathrm{units} / \mathrm{mL})$, and proteases inhibitor cocktail (Calbiochem). BW cells were used as internal control of protein extraction and integrity (data not shown). The supernatant was recovered after 15 minutes centrifugation at $1,500 \mathrm{rpm}$ and the pellet was discarded. Protein concentration was obtained by absorbance at $595 \mathrm{~nm}$ using the Bradford-Lowry method. Total protein extracts of T. crassiceps cysticerci and BW cells were boiled in reducing Laemmli sample buffer, separated by SDS-PAGE (10\% acrylamide), and electroblotted onto nitrocellulose membranes. The membranes were blocked overnight in TBST buffer (10 mM Tris- $\mathrm{HCl}, \mathrm{pH}$ 7.4, $100 \mathrm{mM} \mathrm{NaCl}, 0.5 \%$ Tween 20 ) containing $1 \%$ BSA with $3 \%$ dry milk. Then, different membranes were washed five times in TBST and separately incubated for 2.5 hours in presence of $\alpha$-ERK $(1 \mu \mathrm{g} / \mu \mathrm{L}$, Santa Cruz Biotechnology) and $\alpha$-pERK $(1: 2000$, Cell Signaling). After this first incubation, membranes were washed three times in TBST and subsequently incubated for 1 hour in presence of $\alpha$-mouse IgG HRP (1:2000, Amersham) for pERK and $\alpha$-rabbit IgG HRP ( $1: 1500$, Amersham) for ERK. Immediately after, the bands were visualized using 
the ECL system according to the manufacturer's instructions (Super Signal ECL, Pierce). Chemiluminescent signals were captured on Kodak Bio-Max film.

2.5. Specific Detection of ERK-Like Protein in T. crassiceps Cysticerci by Flow Cytometry. T. crassiceps and mouse spleen cells were extracted by tissue disruption from cultured treated and untreated parasites. $2 \times 10^{6}$ cells for each treatment were incubated at $4^{\circ} \mathrm{C}$ for 20 minutes in presence of $\alpha$-CD3, $\alpha$ CD $4, \alpha-\mathrm{CD} 8, \alpha$-CD 19 , and $\alpha$-macrophages antibodies (as the surface antibodies) and subsequently washed in sterile PBS $1 \mathrm{X}$ staining. Next, cells were centrifuged at 1,500 rpm for 5 minutes and incubated in GolgiPlug (BD,Biosciences) for 3 hours. Immediately, cells were washed in Perm/Wash buffer (BD,Biosciences) and centrifuged at 1,500 rpm for 5 minutes. After this, cells were separately incubated in presence of $\alpha$ ERK $1 \mu \mathrm{g} / \mu \mathrm{L}$ (Santa Cruz, Biotech) at room temperature for 20 minutes, and subsequently washed in PBS 1X staining. Immediately after, cells were centrifuged at 1,500 rpm for 5 minutes. Cell pellets were separately resuspended in presence of FITC-conjugated goat anti-rabbit antibody and incubated at $4^{\circ} \mathrm{C}$ for 30 minutes in the dark. After this, cells were washed in PBS 1X-staining and centrifuged at 1,500 rpm for 5 minutes. Cell pellets were resuspended in $500 \mu \mathrm{L}$ of PBS $1 \mathrm{X}$ staining in absence of light and analyzed by flow cytometry using an FACS Calibur (BD, Biosciences). Data were analyzed with the FlowJo software.

2.6. ERK-Like Protein Location on T. crassiceps Cells by Immunochemistry. $E_{2}$-treated $T$. crassiceps cysticerci were washed with PBS 1X, embedded in Tissuetek (Triangle Biomedical Science), and frozen at $-80^{\circ} \mathrm{C}$. Parasite tissue sections $(10 \mu \mathrm{M})$ were fixed with $4 \%$ paraformaldehyde for 30 minutes, washed three times in PBS, and blocked for 30 minutes with RPMI medium containing 0.5\% BSA and 5\% FBS (Hernández-Bello et al. [34]). Cross-sections were then incubated with a $1: 500$ dilution of the polyclonal $\alpha$ ERK (Santa Cruz, Biotech) for 45 minutes at $37^{\circ} \mathrm{C}$, washed with PBS, and then incubated with fluorescein isothiocyanate (FITC)-conjugated goat anti-rabbit antibody (Zymed) at 1 : 500 dilution. Control experiments were assessed incubating the thick tissue sections in presence of only the FITCconjugated goat anti-rabbit antibody at the same dilution. To eliminate background fluorescence, samples were contrasted with $0.025 \%$ Evans Blue for 10 minutes. After two single washings, samples were mounted in Vectashield mounting medium (Vector Laboratories Inc.) and examined with a Carl Zeiss epifluorescence microscope at 10X, 40X and 100X magnifications (Carl Zeiss, Germany) [34].

2.7. ERK-Like Protein Sequencing by 2-dimension Electrophoresis and Mass Spectrometry. Total protein from cultured T. crassiceps cysticerci was extracted and properly quantified as described before. Protein samples were placed in a buffer containing $8 \mathrm{M}$ urea, 2\% CHAPS, $50 \mathrm{mM}$ DTT, IPG pH 4-7 (Bio-Rad), and bromophenol blue. Immediately after, protein samples were incubated overnight with the first-dimension gel (Amersham). Once they were properly hydrated, the first-dimension gel was isoelectrofocused with a constant voltage on a lineal electric gradient. After this, the gel was equilibrated in a buffer containing $6 \mathrm{M}$ urea, 2\% SDS, $375 \mathrm{mM}$ Tris pH 8.8, 2\% DTT, and 20\% glycerol for 15 minutes. Next, the same equilibration process was performed using iodoacetamide $25 \mathrm{mg} / \mathrm{mL}$ instead of DTT. Once equilibrated, the gel was separated according to the molecular size of each protein in a second-dimension gel (PAGE-SDS al 12.5\%). Finally, the bidimensionally separated gel was electroblotted onto nitrocellulose membranes and a $\alpha$-ERK Western blot was carried out, as mentioned before. Only the immunodetected point, corresponding to the expected molecular weight and to the predicted isoelectrical point, was cut out and sequenced by mass spectrometry.

2.8. Experimental Design and Statistical Analysis. $E_{2}$ and ERK inhibitor II concentration-response and time-response curves were estimated in six independent experiments, each performed with ten cysticerci, freshly extracted from different infected donor mice, and replicated in 24 different wells. The response variable used in statistical analysis was the sum of buds in the 24 wells with each treatment along the time of exposure of each experiment. Data of the six replications of each experiment were pooled and expressed as their average $+/-$ standard deviation. All optical densitometries as well as the mean of the fluorescence in the flow cytometry analysis was calculated for six different experiments and expressed as the average $+/-$ standard deviation. Data were analyzed using either Student's $t$-test or one-way ANOVA and a subsequent Dunnet's Multiple Comparison Test, depending on the experimental design. Differences were considered statistically significant when $P<.05$.

\section{Results}

3.1. E2 Stimulates while ERK Inhibitor Diminishes the Reproduction of Taenia Crassiceps. The number of buds (which directly reflects the reproductive rate in this parasite) in cultured $T$. crassiceps cysticerci clearly increased by addition of $17 \beta$-estradiol in a concentration-dependent manner. Compared to control groups, $\mathrm{E}_{2}$ increased the parasite reprodcution rate up to 3 -folds, from the lowest concentration on $100 \mathrm{nM}$ up to higher pharmacologic concentrations such as 1 and $10 \mu \mathrm{M}$, without affecting parasite viability (Figure 1(a)). In contrast, the ERK inhibitor showed the opposite effect on the number of cysticercus buds, although this effect was significant only at the highest concentrations ( 1 and $10 \mu \mathrm{M}$ ), which suggests that the ERK inhibitor effect was also dependent on concentration (Figure 1(a)). In addition to the concentration effects, the proliferative action of $E_{2}$ on parasite reproduction was maintained throughout the culture time, reaching a 3-fold higher number of buds than that in untreated cysticerci at around five days of in vitro culture (Figure 1(b)). Interestingly, compared with control cysticerci, ERK inhibitor treatment of cysticerci had no significant effects on parasite reproduction (Figure 1(b)). However, it was clear that the ERK inhibitor completely blocked the $E_{2}$-dependent proliferative effect (Figure 1(b)), emphasizing the importance of both $E_{2}$ and ERK-like in the reproduction of the $T$. crassiceps cysticerci. 




- Estradiol

ERK inhibitor

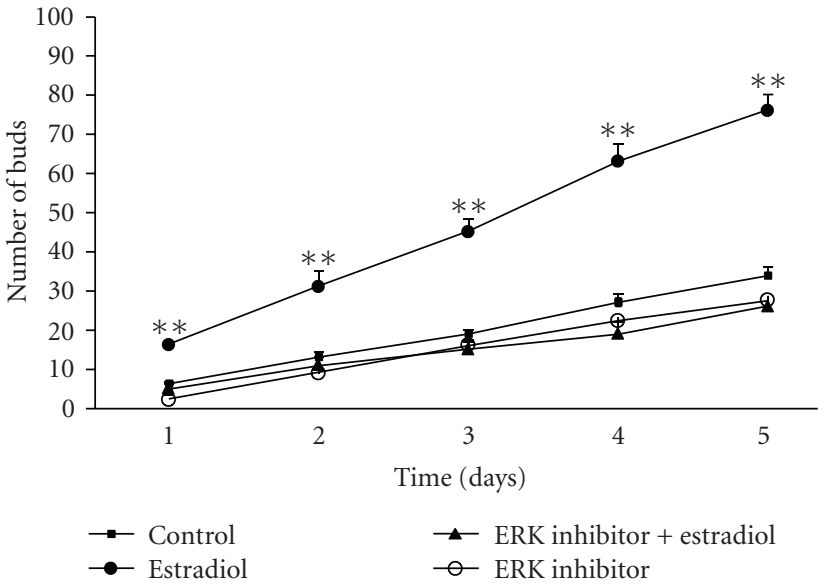

(b)

FIgURE 1: Concentration-response and response-time curves. $17 \beta$-estradiol augments the number of buds in Taenia crassiceps under physiologic concentrations $(0.1 \mu \mathrm{M})$. Specific inhibition of ERK blocks the $17 \beta$-estradiol effect on the parasite, resulting in a similar number of buds between control and ERK inhibitor-treated cysticerci; (a) 17 $\beta$-estradiol effect was progressively increasing during the five days of in vitro culture, whereas ERK inhibitor $0.5 \mu \mathrm{M}$ did not modify parasite reproduction when compared to control cysticerci, even in presence of $17 \beta$-estradiol $0.1 \mu \mathrm{M}$, and (b) Control $=$ Parasites treated with the vehicle where hormone and inhibitors were dissolved; ${ }^{* *} P<.05$.
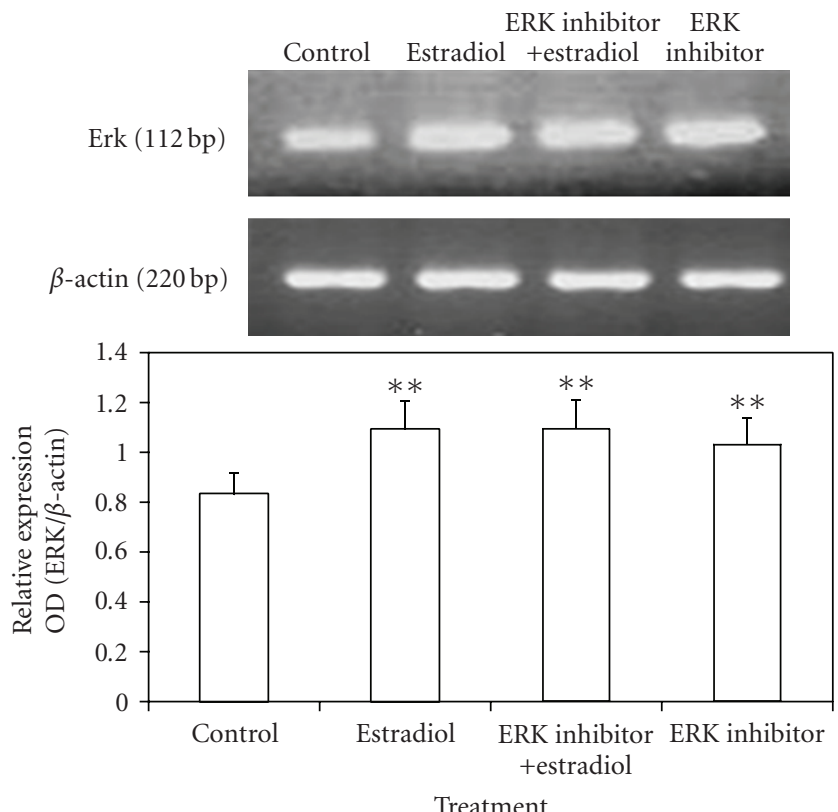

Figure 2: ERK-like expression in Taenia crassiceps. A single band of approximately $112 \mathrm{bp}$ corresponding to ERK was detected in all in vitro treated cysticerci. Unexpectedly, either $17 \beta$-estradiol or ERK inhibitor treatment significantly induced ERK-like expression, related to control cysticerci. $\beta$-actin was used as control gene of constitutive expression. Optical densitometry was performed on $2 \%$ agarose gel from six independent experiments. Control = Parasites treated with the vehicle where hormone and inhibitors were dissolved; ${ }^{* *} P<.05$.

3.2. ERK-Like Gene Expression in Taenia Crassiceps. Using specific primers designed considering the most conserved sequences of all reported ERKs 1/2, a band of $112 \mathrm{bp}$ was amplified and corresponds to the expected molecular weight of the ERK-like gene in T. crassiceps and in the mouse (internal control of expression, data not shown). Interestingly, a significant increase in expression of the ERKlike gene was observed in response to $E_{2}$ and ERK inhibitor, even if the inhibitor was in presence of the steroid hormone (Figure 2).

\subsection{E Increases ERK-Like Protein Phosphorylation but not the} Total Quantity of the Native Protein. Native ERK-like protein $(55 \mathrm{KDa})$ was detected in untreated, $E_{2}$ treated, and ERK inhibitor-treated parasites. Contrary to the observations made by RT-PCR, no changes in total protein quantity were observed with any of the treatments (Figure 3(a)). Interestingly, when the phosphorylated form of ERK-like (pERK-like) protein was analyzed, it was evident that $E_{2}$ increases ERK-like protien phosphorylation 4 folds compared to untreated parasites (Figure 3(b)). Interestingly, ERK inhibitor treatment partially blocked the estradiol stimulated ERK-like protein phosphorylation, without returning it to basal levels (Figure 3(b)).

3.4. ERK-Like Protein Is Specifically Detected in Taenia Crassiceps and Is Not a Contamination Product from Host Immune Cells. Flow cytometry analysis firstly showed that T. crassiceps cells were different in size and complexity from mouse spleen cells (Figure 4). In fact, parasite cells were approximately 3 folds smaller than mouse spleen cells and exhibited poor complexity (data not shown). In addition, parasite cells showed no expression of the membrane markers CD3, CD4, CD8, and CD19, typically present in different types of mammalian leukocytes (Figure 4(a)). However, paramyosin (Ag-B, an exclusive component of the cytoskeleton of cestodes and insects) was clearly detected in T. crassiceps cells but not in host splenocytes (Figure 4(a)). Thus, the ERK-like protein was exclusively recognized on 



(a)


(b)

FIGURE 3: ERK-like protein detection in Taenia crassiceps. Total ERK-like protein in T. crassiceps was not modified by $17 \beta$-estradiol or ERK inhibitor treatments (a), contrary to that observed in ERK-like gene expression. Nevertheless, $17 \beta$-estradiol specifically induced phosphorylation of ERK-like by four-fold respect to control groups (b). Optical densitometry was performed on $10 \%$ acrylamide gel from six independent experiments. Control $=$ Parasites treated with the vehicle where hormone and inhibitors were dissolved; ${ }^{* *} P<.05$.

T. crassiceps cells, because the FACS analysis was performed on parasite cells $\mathrm{Ag}-B^{+} / \mathrm{CD}^{-} / \mathrm{CD} 4^{-} / \mathrm{CD}^{-} / \mathrm{CD} 19^{-}$. No significant differences were observed in the fluorescence intensity related to the ERK-like protein in untreated and $E_{2}$ treated parasites (Figure 4(b)).

3.5. ERK-Like Protein Is Present in the Subtegument Cells of Taenia Crassiceps Cysticerci. Up to this point, experimental evidence indicates that the ERK-like protein is expressed in T. crassiceps cysticerci and that this is not a contamination product from host cells. In addition, on well-preserved T. crassiceps tissue (Figure 5(a)), immunochemistry assays were perfomed and the results showed that parasite cells express ERK-like protein mainly in the subtegument tissue of the cysticercus but not in tegument (Figures 5(c) and 5(d)). As expected, T. crassiceps tissue incubated only in presence of the secondary antibody did not give any positive signal related to ERK (Figure 5(b)), which suggests that the experimental conditions were optimal for detecting exclusively parasite cells presenting ERK-like molecules without false positive signals.

3.6. Sequencing and Phylogenetic Analysis of the Taenia Crassiceps ERK-Like Protein. Total proteins from $E_{2}$-treated parasites were separated in a $\mathrm{pH}$ range of 4-7, according to their isoelectrical point (IP) and molecular weight (Figure 6(a)). Moreover, a well-defined dot around pH 6.00, corresponding to the IP of most of the sequenced ERK $1 / 2$, was recognized with high specificity by means of a single Western blot (Figure 6(b)). Interestingly, the ERK-like sequence showed high homology (60\%) to ERK 1/2 from yeast, chicken, and mouse. Concomitantly, we were able to detect the activation motif TEY (threonine-glutaminetyrosine) on the parasite's ERK-like protein sequence, which is typically present in all ERK $1 / 2$ sequenced from several vertebrate and invertebrate organisms. Finally, the highly conserved amino acid sequence, NILTLHNVANTVMKNPAMISKNLLR, was identified from the parasite's ERK-like 

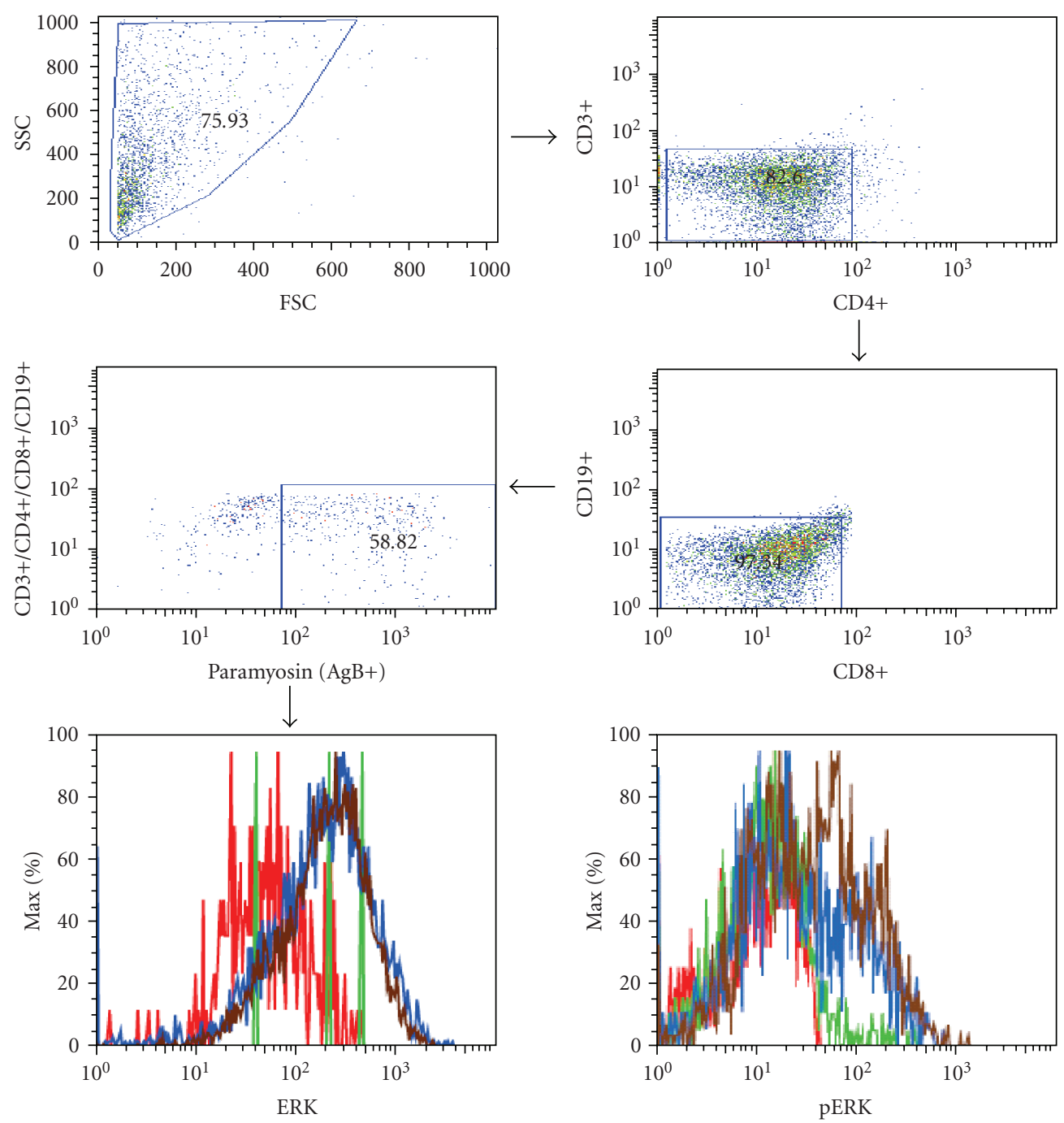

(a)



(b)

FIgURE 4: Specific detection of ERK-like in Taenia crassiceps. FACS assays showed that ERK-like detected in T. crassiceps was not a contamination product from host immune cells $\mathrm{CD} 3+, \mathrm{CD} 4+, \mathrm{CD} 8+$, and $\mathrm{CD} 19+$. As expected, ERK-like was specifically detected in paramyosin positive cells, a cytoskeleton protein only present in cestodes and some insects (a). By using the Mean of Fluorescence Intensity (MFI), no differences in total ERK-like and pERK were observed between control and $17 \beta$-estradiol cysticerci (b). Control = Parasites treated with the vehicle where hormone and inhibitors were dissolved. Red $=$ unstained cells; green $=$ control parasites; blue $=\mathrm{E}_{2}$-treated parasites; brown $=$ ERK inhibitor-treated parasites; $S S C=$ Side Scatter; FSC $=$ Forward Scatter; $\mathrm{pERK}=$ ERK phosphorylated form; MFI $=$ Fluorescence average. 


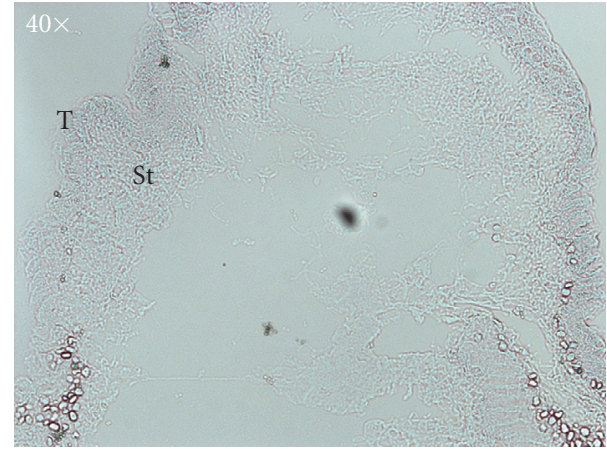

(a)



(c)

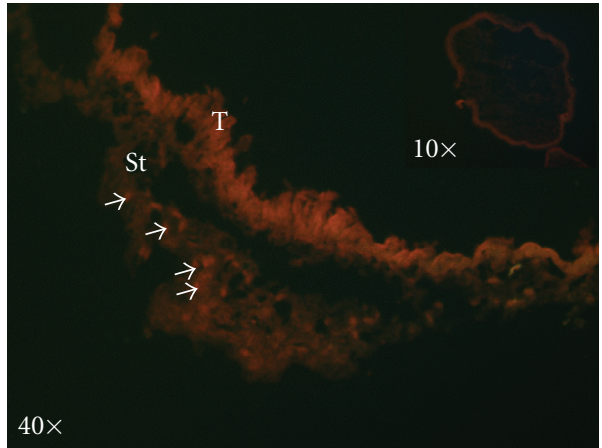

(b)



(d)

FIgURE 5: ERK-like location in Taenia crassiceps by immunocytochemistry. (a) Transversal section of one T. crassiceps cysticercus where tegument, subtegument, and cells are observed with no staining. (b) Parasite cross-section incubated with FITC-conjugated goat anti-rabbit antibody, as staining control. Nonreacting cells are shown in red at $10 \times$ and $40 \times$. Unspecific detection of ERK-like was not observed during our experiments. (c) Specific detection of ERK-like (green fluorescent) was located in parasite cells mainly disposed along subtegument tissue, $40 \times$. (d) A magnification of $100 \times$ shows in detail the T. crassiceps cells expressing ERK-like exclusively on subtegument tissue. $\mathrm{T}=$ Tegument tissue; $\mathrm{St}=$ Subtegument tissue.



(a)



(b)

FIGURE 6: ERK-like detection by 2DE and protein sequencing. Total protein of in vitro cultured T. crassiceps was resolved in a double dimension gel (a). A well-defined $\operatorname{dot}(\sim 55 \mathrm{KDa}, \mathrm{pH}=6.8)$ was detected in $T$. crassiceps and then purified from the gel for sequencing (b). MW $=$ Molecular weight marker. 
protein, which strongly suggests that this protein also conserves serine-threonine kinase activity and could influence phosphorylation of other parasite kinases (data not shown).

\section{Discussion}

As previously reported, $17 \beta$-estradiol exerts a direct proliferative effect on Taenia crassiceps cysticercus reproduction, which is not necessarily mediated by the host immune system, but through a classic nuclear receptor in the parasite [22]. However, alternative mechanisms through which $\mathrm{E}_{2}$ can affect the parasite, securing its reproduction and establishment in an immuncompetent host, have not been completely explored yet. The aim of the present study was to investigate the participation of a signaling pathway mediated by second messenger cascades, which may be responsive to sex steroids that are highly conserved throughout the species and involved in cell proliferative processes. Thus, we explored the signaling pathway dependent on ERK-like protein, a member of the MAPK kinases which can be activated by several extracellular signals and generate rapid responses inside the cell, and the effect of the ERK inhibitor on ERKlike protein participation in parasite reproduction.

Interestingly, we found that, at progressively higher $17 \beta$-estradiol concentrations, the number of T. crassiceps cysticercus buds reached a maximum value. The opposite response was observed when ERK inhibitor was tested in culture. As concentration of ERK inhibitor increased, parasite reproduction progressively decreased. On the other hand, the $\mathrm{E}_{2}$ effect was enhanced as time passed, reaching its maximum effect on parasite reproduction at day five of in vitro culture, which supports that $\mathrm{E}_{2}$ effects are concentration dependent. Nevertheless, no time-dependent response was found when ERK inhibitor was tested, although this inhibitor completely blocked the $\mathrm{E}_{2}$-dependent proliferative effect, suggesting that parasite ERK-like protein is directly involved in mediating the crosstalk between the hormonal microenvironment (exogenous $\mathrm{E}_{2}$ ) and parasite reproduction. These findings show a marked concentration and time-dependent pattern in the effects of $E_{2}$ on cysticercus reproduction. This observation is relevant since it suggests that sex steroids may have similar effects on mammals and parasitic cestodes, a hypothesis that evokes the wide range of steroid hormone actions not only in many different cell types but also along the phylogenetic scale, among distantly related organisms.

Moreover, determination of the actions of $\mathrm{E}_{2}$ and ERK inhibitor on T. crassiceps cysticerci was important. This was approached by analyzing the ERK-like gene expression in the parasite as well as its translation to functional proteins that mediate the $\mathrm{E}_{2}$ effects. In view of this, a band corresponding to ERK-like gene was amplified from T. crassiceps larval tissue using specific primers designed for the most conserved regions of these genes, previously reported in mammals such as mouse, rat, and human, as well as in yeast, birds, and amphibian. Unexpectedly, not only the ERK-like gene is expressed in the parasite, but it can also be overregulated by $17 \beta$-estradiol. However, a similar effect was observed when parasites were cultured in presence of ERK inhibitor. This unexpected finding suggests that helminth parasites could have developed a positive feedback mechanism which is able to sense changes in the expression of very essential molecules such as MAPK kinases and maintain their activity in order to assure viability and reproduction of the parasite. On the other hand, the effects of sex steroids on parasite MAPK kinases gene expression, which are in charge of mediating the functionality of the whole pathway, have been scarcely explored. The results obtained in this study showed that this type of parasite genes is differentially regulated by exogenous sex steroids, which could be occurring in vivo from host to parasite. Also, this finding offers an alternative explanation of why $T$. crassiceps cysticerci grow better in the female mouse than in the male [20], emphasizing the molecular crosstalk between host and parasite, which is in turn differentially influenced by the hormonal microenvironment of each gender.

It is important to underline that proteins involved in signal transduction pathways, lead their functions by being phosphorylated; it was therefore crucial to determine the corresponding ERK-like protein in the parasite and to analyze its phophorylation pattern in response to $17 \beta$ estradiol and ERK inhibitor treatments. Unexpectedly, one single band corresponding to ERK-like protein was detected in T. crassiceps, while most mammalian species exhibit a characteristic doublet. This finding suggests that, along many years of coevolution between the host and the parasite, several molecules, such as genes or proteins, may have been lost or "economized", passing their functions onto others that conserve similar structure and can therefore trigger the same effects due to a complex process of "molecular hypertrophy", by which a few molecules can exert many functions. The fact that the ERK-like protein differs from its homolog in mammalian cells supports two very important aspects of this study: (a) that the MAPK kinase detected in the parasite is not produced by contamination from host immune cells and (b) that, although both proteins have different characteristics, they probably conserve a high degree of similarity in their catalytic domains, which makes them recognizable with the same antibody and assures the suitable function for transducing signals in both organisms. In addition, $17 \beta$-estradiol treatment differentially stimulated the phosphorylation of ERK-like protein, which strongly supports that only parasitic ERK-like protein is expressed and regulated by exogenous estrogens but also that this MAPK kinase can be translated to a functional protein, able to be activated through $\mathrm{E}_{2}$-stimulated phosphorylation processes. This result suggests again that the mechanisms of action of steroid hormones on target cells are poorly diversified among species, maintaining similar and successful strategies from the simplest to the most complex organisms.

On the other hand, it was critical to determine that the detected and analyzed ERK-like protein was exclusively found in the Taenia crassiceps cysticercus and not a consequence of host immune cell contamination, because, as shown elsewhere, there is extremely high interaction between parasites and immune cells, which may eventually lead to leukocyte invasion into several parasitic tissues [35]. For this reason, an alternative use of flow cytometry was used to 
differentiate proteins from $T$. crassiceps and the murine host by identifying exclusive molecules of the parasite which are neither synthesized nor expressed by the host. This is the case of paramyosin, a muscle protein found only in invertebrates such as Drosophila melanogaster, Caenorhabditis elegans, Taenia solium, and T. saginata [36]. The flow cytometry studies showed that presence and phosphorylation pattern of the analyzed ERK-like protein belonged specifically to the parasite, because paramyosin was only detected in $T$. crassiceps cells, where this MAPK kinase was also found and studied. In contrast, cells extracted from mouse spleen were not recognized by the $\alpha$-paramyosin antibody, but they were positive for CD3, CD4, CD8, CD19, and macrophage antibodies, contrary to parasite cells.

These results demonstrate that the analyzed parasite ERK-like protein is in fact from Taenia crassiceps origin and not from other sources and simultaneously accentuate the potential use of flow cytometry for differential identification of molecules from organisms with extremely close contact, such as this parasite and its host.

Worth of mention is that the ERK-like protein was not only detected at messenger RNA and protein level but also localized inside the parasite cell. Interestingly, parasitic cells expressing ERK-like protein were exclusively located at the subtegument tissue, where most of the muscle and nephridium cells are found. This result suggests that the ERK-like protein is importantly involved in parasite motility and excretion, as well as in reproductive functions, which together maintain parasite viability and proliferation.

Finally, the protein sequence of the ERK-like protein showed a remarkable degree of conservation of certain segments, such as the activation domain, and functions, such as the serine-threonine kinase activity, both of them characteristic of these MAPK kinases. In fact, protein sequences from mammalian and high invertebrate ERK $1 / 2$ are different to the parasite ERK-like protein, but closely related regarding the conserved domains, which suggests that parasites have developed similar structures as their host homologs, probably keeping only the catalytic domains in order to secure the basic functions of important proteins such as the ERK family. This hypothesis supports that development of proteins which can recognize the host's growth factors represents advantages in parasite metabolism economy, because the pathogen does not need to synthesize all molecules involved in a pathway but can take them directly from its host. This benefits the processes of reproduction, establishment, and immune evasion, among other important aspects of parasite life.

In conclusion, this work describes a functionally ERKlike protein in T. crassiceps. This MAPK kinase showed great capacity to transduce signals evoked by $17 \beta$-estradiol in the parasite. It is important to mention that much information about the effects of the host hormonal microenvironment on parasite physiology has been generated in recent years $[15,37-39]$. Our results then contribute to understand the mechanisms by which the host microenvironment affects the parasite. Furthermore, the evolutionary origin of the molecules described herein, which facilitate exploitation of the host's hormones, is worth studying. In particular, whether those genes were acquired by the parasite through horizontal gene transfer or evolved by mimicry, or simply from common ancestral genes, remains to be defined. Finally, our findings may help to understand, at molecular and evolutionary levels, several aspects of the crosstalk between host and parasite, of the sexual dimorphism of the immune response, and may provide information on new parasite targets for designing specific antihelminth drugs.

\section{Acknowledgments}

Financial support was provided by Grants no. 136430-N and 40072-A from CONACyT to J. Morales-Montor and Grant no. IN21271 from the Programa de Apoyo a Proyectos de Innovación Tecnológica, Dirección General de Asuntos del Personal Académico, UNAM to J. Morales-Montor. Galileo Escobedo has a postdoctoral fellowship by the Dirección General de Asuntos del Personal Académico (DGAPA), UNAM. The authors are grateful to Isabel Pérez Montfort for correcting the English version of the manuscript.

\section{References}

[1] L. O. Murphy and J. Blenis, "MAPK signal specificity: the right place at the right time," Trends in Biochemical Sciences, vol. 31, no. 5, pp. 268-275, 2006.

[2] M. Krishna and H. Narang, "The complexity of mitogenactivated protein kinases (MAPKs) made simple," Cellular and Molecular Life Sciences, vol. 65, no. 22, pp. 3525-3544, 2008.

[3] S. Wray and K. Noble, "Sex hormones and excitationcontraction coupling in the uterus: the effects of oestrous and hormones," Journal of Neuroendocrinology, vol. 20, no. 4, pp. 451-461, 2008.

[4] M. Whitaker, "Calcium signalling in early embryos," Philosophical Transactions of the Royal Society B, vol. 363, no. 1495, pp. 1401-1418, 2008.

[5] M. Maioli and C. Ventura, "Protein kinase C control of gene expression," Critical Reviews in Eukaryotic Gene Expression, vol. 11, no. 1-3, pp. 243-267, 2001.

[6] R. Katso, K. Okkenhaug, K. Ahmadi, S. White, J. Timms, and M. D. Waterfield, "Cellular function of phosphoinositide 3kinase: implications for development, immunity, homeostasis, and cancer," Annual Review of Cell and Developmental Biology, vol. 17, pp. 615-675, 2001.

[7] S. Chittaranjan, M. McConechy, Y.-C. C. Hou, J. D. Freeman, L. DeVorkin, and S. M. Gorski, "Steroid hormone control of cell death and cell survival: molecular insights using RNAi," PLoS Genetics, vol. 5, no. 2, article e1000379, 2009.

[8] P. E. Micevych, J. Kuo, and A. Christensen, "Physiology of membrane oestrogen receptor signalling in reproduction," Journal of Neuroendocrinology, vol. 21, no. 4, pp. 249-256, 2009.

[9] H. J. Rohe, I. S. Ahmed, K. E. Twist, and R. J. Craven, "PGRMC1 (progesterone receptor membrane component 1): a targetable protein with multiple functions in steroid signaling, P450 activation and drug binding," Pharmacology and Therapeutics, vol. 121, no. 1, pp. 14-19, 2009.

[10] J. L. Novotny, A. M. Simpson, N. J. Tomicek, T. S. Lancaster, and D. H. Korzick, "Rapid estrogen receptor- $\alpha$ activation improves ischemic tolerance in aged female rats through a novel protein kinase Ce-dependent mechanism," Endocrinology, vol. 150, no. 2, pp. 889-896, 2009.

[11] V. Levin-Salomon, I. Maayan, L. Avrahami-Moyal, I. Marbach, O. Livnah, and D. Engelberg, "When expressed in yeast, 
mammalian mitogen-activated protein kinases lose proper regulation and become spontaneously phosphorylated," Biochemical Journal, vol. 417, no. 1, pp. 331-340, 2009.

[12] T. Tanoue, M. Adachi, T. Moriguchi, and E. Nishida, "A conserved docking motif in MAP kinases common to substrates, activators and regulators," Nature Cell Biology, vol. 2, no. 2, pp. 110-116, 2000.

[13] M. Ebisuya, K. Kondoh, and E. Nishida, "The duration, magnitude and compartmentalization of ERK MAP kinase activity: mechanisms for providing signaling specificity," Journal of Cell Science, vol. 118, no. 14, pp. 2997-3002, 2005.

[14] S. Yoon and R. Seger, "The extracellular signal-regulated kinase: multiple substrates regulate diverse cellular functions," Growth Factors, vol. 24, no. 1, pp. 21-44, 2006.

[15] G. Escobedo, C. W. Roberts, J. C. Carrero, and J. MoralesMontor, "Parasite regulation by host hormones: an old mechanism of host exploitation?" Trends in Parasitology, vol. 21, no. 12, pp. 588-593, 2005.

[16] M. Spiliotis, C. Konrad, V. Gelmedin, et al., "Characterisation of EmMPK1, an ERK-like MAP kinase from Echinococcus multilocularis which is activated in response to human epidermal growth factor," International Journal for Parasitology, vol. 36, no. 10-11, pp. 1097-1112, 2006.

[17] J. Ellis, M. Sarkar, E. Hendriks, and K. Matthews, "A novel ERK-like, CRK-like protein kinase that modulates growth in Trypanosoma brucei via an autoregulatory C-terminal entension," Molecular Microbiology, vol. 53, no. 5, pp. 1487 1499, 2004.

[18] C. Larralde, J. Sotelo, R. M. Montoya, et al., "Immunodiagnosis of human cysticercosis in cerebrospinal fluid. Antigens from murine Taenia crassiceps cysticerci effectively substitute those from porcine Taenia solium," Archives of Pathology and Laboratory Medicine, vol. 114, no. 9, pp. 926-928, 1990.

[19] C. Larralde, E. Sciutto, L. Huerta, et al., "Experimental cysticercosis by Taenia crassiceps in mice: factors involved in susceptibility," Acta Leidensia, vol. 57, no. 2, pp. 131-134, 1989.

[20] C. Larralde, J. Morales, I. Terrazas, T. Govezensky, and M. C. Romano, "Sex hormone changes induced by the parasite lead to feminization of the male host in murine Taenia crassiceps cysticercosis," Journal of Steroid Biochemistry and Molecular Biology, vol. 52, no. 6, pp. 575-580, 1995.

[21] L. I. Terrazas, R. Bojalil, T. Govezensky, and C. Larralde, "Shift from an early protective TH1-type immune response to a late permissive TH2-type response in murine cysticercosis (Taenia crassiceps)," Journal of Parasitology, vol. 84, no. 1, pp. 74-81, 1998.

[22] G. Escobedo, C. Larralde, A. Chavarria, M. A. Cerbón, and J. Morales-Montor, "Molecular mechanisms involved in the differential effects of sex steroids on the reproduction and infectivity of Taenia crassiceps," Journal of Parasitology, vol. 90, no. 6, pp. 1235-1244, 2004.

[23] J. Morales-Montor, G. Escobedo, M. Rodriguez-Dorantes, N. Téllez-Ascencio, M. A. Cerbón, and C. Larralde, "Differential expression of AP-1 transcription factor genes c-fos and c-jun in the helminth parasites Taenia crassiceps and Taenia solium," Parasitology, vol. 129, no. 2, pp. 233-243, 2004.

[24] J. A. Vargas-Villavicencio, C. Larralde, M. A. De León-Nava, G. Escobedo, and J. Morales-Montor, "Tamoxifen treatment induces protection in murine cysticercosis," Journal of Parasitology, vol. 93, no. 6, pp. 1512-1517, 2007.

[25] M. J. Kelly and E. J. Wagner, "Estrogen modulation of G-protein-coupled receptors," Trends in Endocrinology and Metabolism, vol. 10, no. 9, pp. 369-374, 1999.
[26] A. Guiochon-Mantel, "Regulation of the differentiation and proliferation of smooth muscle cells by the sex hormones," Revue des Maladies Respiratoires, vol. 17, no. 2, pp. 604-608, 2000.

[27] E. R. Levin, "Bidirectional signalling between the estrogen receptor and the epidermal growth factor receptor," Molecular Endocrinology, vol. 17, pp. 309-317, 2003.

[28] T. Simoncini, E. Rabkin, and J. K. Liao, "Molecular basis of cell membrane estrogen receptor interaction with phosphatidylinositol 3-kinase in endothelial cells," Arteriosclerosis, Thrombosis, and Vascular Biology, vol. 23, no. 2, pp. 198-203, 2003.

[29] C.-W. Wong, C. McNally, E. Nickbarg, B. S. Komm, and B. J. Cheskis, "Estrogen receptor-interacting protein that modulates its nongenomic activity-crosstalk with Src/Erk phosphorylation cascade," Proceedings of the National Academy of Sciences of the United States of America, vol. 99, no. 23, pp. 14783-14788, 2002.

[30] M. I. Boulware, J. P. Weick, B. R. Becklund, S. P. Kuo, R. D. Groth, and P. G. Mermelstein, "Estradiol activates group I and II metabotropic glutamate receptor signaling, leading to opposing influences on cAMP response element-binding protein," Journal of Neuroscience, vol. 25, no. 20, pp. 50665078, 2005.

[31] A. Migliaccio, G. Castoria, M. D. Domenico, et al., "Steroidinduced androgen receptor-oestradiol receptor $\beta$-Src complex triggers prostate cancer cell proliferation," EMBO Journal, vol. 19, no. 20, pp. 5406-5417, 2000.

[32] P. G. Agron, S. L. Reed, and J. N. Engel, "An essential, putative MEK kinase of Leishmania major," Molecular and Biochemical Parasitology, vol. 142, no. 1, pp. 121-125, 2005.

[33] F. S. Freeman, "Studies on the biology of Taenia crassiceps (zeder 1800) rudolphi, 1810 (cestoda)," Canadian Journal of Zoology, vol. 40, pp. 969-990, 1962.

[34] R. Hernández-Bello, R. M. Bermúdez-Cruz, R. FonsecaLiñán, et al., "Identification, molecular characterisation and differential expression of caveolin-1 in Trichinella spiralis maturing oocytes and embryos," International Journal for Parasitology, vol. 38, no. 2, pp. 191-202, 2008.

[35] T. V. Rajan, L. Ganley, N. Paciorkowski, L. Spencer, T. R. Klei, and L. D. Shultz, "Brugian infections in the peritoneal cavities of laboratory mice: kinetics of infection and cellular responses," Experimental Parasitology, vol. 100, no. 4, pp. 235$247,2002$.

[36] M. Maroto, J. J. Arredondo, M. San Román, R. Marco, and M. Cervera, "Analysis of the paramyosin/miniparamyosin gene. Miniparamyosin is an independently transcribed, distinct paramyosin isoform, widely distributed in invertebrates," Journal of Biological Chemistry, vol. 270, no. 9, pp. 4375-4382, 1995.

[37] M. Waisberg, F. P. Lobo, G. C. Cerqueira, et al., "Schistosoma mansoni: microarray analysis of gene expression induced by host sex," Experimental Parasitology, vol. 120, no. 4, pp. 357$363,2008$.

[38] S. Chatterjee, J. O. De Beeck, A. V. Rao, et al., "Prolonged somatostatin therapy may cause down-regulation of SSTRlike GPCRs on Schistosoma mansoni," Journal of Vector Borne Diseases, vol. 44, no. 3, pp. 164-180, 2007.

[39] F. Remoué, J.-C. Mani, M. Pugnière, A.-M. Schacht, A. Capron, and G. Riveau, "Functional specific binding of testosterone to Schistosoma haematobium 28-kilodalton glutathione S-transferase," Infection and Immunity, vol. 70, no. 2, pp. 601$605,2002$. 



Submit your manuscripts at

http://www.hindawi.com


The Scientific World Journal
